\title{
Buyer power, product assortment and asymmetric retail
}

\section{formats *}

\author{
Ramon Fauli-Oller ${ }^{\dagger} \quad$ and Joel Sandonís ${ }^{\ddagger} \quad$ University of Alicante
}

February 10th 2020

\begin{abstract}
We consider two manufacturers producing two symmetric and independent goods. They sell them through two undifferentiated retailers (homogeneous retailers). Manufacturers propose linear contracts. Before supply contracts are set by producers, retailers decide whether to be a multi-product retailer by carrying the two goods or a single product retailer and sell only one good. In this symmetric setting, we find asymmetric retail formats in equilibrium, which results in lower total welfare compared to a situation where both retailers would be multi-product retailers.
\end{abstract}

${ }^{*}$ We acknowledge financial support from the Spanish Ministerio de Economía y Competitividad and FEDER funds ECO2015-65820-P (MINECO/FEDER) and from Generalitat Valenciana grant PROMETEO/2019/037. Special thanks should be given to Daniel Cardona, who helped us in the proofs of the Propositions. We thank Pedro Albarrán, Lluís Bru, Marc Escrihuela-Villar, Miguel González-Maestre, Angel Hernando, Josefa Tomás and Luis Ubeda for helpful comments. Thanks are also due to the editor, Francis Breedon, an anonymous Associate editor and two anonymous referees. Part of this research was written while Fauli-Oller was visiting the Institut d'Anàlisi Econòmica (CSIC).

${ }^{\dagger}$ Corresponding author. Fundamentos del Análisis Económico (FAE), Universidad de Alicante, Campus de Sant Vicent del Raspeig, E-03071, Alicante, Spain. E-mail address: fauli@ua.es.

${ }^{\ddagger}$ Fundamentos del Análisis Económico (FAE), Universidad de Alicante, Campus de Sant Vicent del Raspeig, E-03071, Alicante, Spain. E-mail address: sandonis@ua.es. 
JEL Classification: L13; L41; L42

keywords: channel power, retail formats, product assortment, multiproduct firms 


\section{Introduction}

The issue of "power" in the marketing channels for consumer products has received considerable attention in the literature (e.g., Messinger and Narasimhan (1995), Johnson (1988), Kadiyali et al. (2000)). As Dukes et al. (2009) report, traditionally manufacturers decided product assortment, and distributed all product lines and varieties through complying retailers. ${ }^{1}$ However, this conventional wisdom has changed nowadays, as it is well documented that the channel power has increasingly shifted from the manufacturers to the retailers over time in such a way that very often manufacturers have to adjust production lines in favor of the retailers' orders. $^{2}$ This is true not only for dominant multiproduct retailers (like for example Walmart, CVS, Target, Amazon or Carrefour), but also for retailers with narrower product lines (such as Aldi) or specialized retailers (like for example Home Depot, Staples or Victoria's Secret), who have also the power to choose their product assortments. Regarding the size of the product assortments, Rhodes and Zhou (2019) point out that, over time, many retailers have aggressively increased the size of their product assortments with the aim to become one-stop shops. As they report, "The Food Marketing Institute estimates that between 1975 and 2013, the number of products in an average US supermarket increased from around 9,000 to almost 44,000. Nevertheless,

\footnotetext{
${ }^{1}$ See for example the European Commision Report (2005) on abuse of dominant position by Coca-Cola. It describes how "the Commission's investigation into Coca-Cola's commercial activities, namely exclusivity related practices, target and growth rebates and assortment related arrangements, identified competition concerns byand-large common to all three types of practices, namely the foreclosure of competitors, reduction of the variety of choice for the consumer and, consequently, avoidance of downward pressure on prices. Evidence indicated that one or more of the above practices existed in all the EC Member States, Iceland and Norway".

${ }^{2}$ Some of the reasons that have been cited to explain this increasing retailer power are: the intense competition among manufacturers, the introduction of successful private label brands, the increased concentration at the retail level, the use of advanced information technologies and the scarcity of shelf space due to a large number of new product introductions (Kadiyali et al. (2000)).
} 
and somewhat puzzlingly, in most retail markets large players like Wal-Mart or Amazon still coexist with many smaller retailers whose product ranges are much narrower" ${ }^{3}$ In this paper, we want to provide a theoretical explanation for the observed successful coexistence of different retail formats, which does not rely either on consumers' preferences for one-stop shopping as for example in Johansen and Nilssen (2016) and Rhodes and Zhou (2019), or on assortment costs, as in Dukes et al. (2009), and it is not a consequence either of the existence of upstream market power, like in Avenel and Caprice (2006). In our framework, the existence of different retail formats in equilibrium arises from the retailers' strategic incentives to reduce assortment, as a way to shape their interaction with suppliers. We show that powerful retailers may have a strategic incentive to reduce assortment as a way to foster competition between manufacturers for the scarce shelf space, which shifts bargaining power to the retailer, resulting into better deals in the intermediate market and so larger retailer's profits. We show that, even if retailers are ex-ante symmetric, they might end up offering different levels of assortment in equilibrium, which is consistent with the well documented coexistence of different retail formats in the market. ${ }^{4}$

In our main model, we consider two suppliers producing two symmetric and independent goods with linear demand. The goods are sold through two undifferentiated retailers that compete à la Cournot in the final market. Trade between manufacturers and retailers takes place through linear contracts. Before the linear supply contracts are set by the producers, we allow the retailers to (independently) choose whether to be a multi-product retailer (selling

\footnotetext{
${ }^{3}$ Fernie et al. (2003) pp. 197 document, "....it is not surprising that Walmart chose Germany as its entry market for Europe because of its strong discounter culture. This is reflected in its large number of hypermarkets and hard discounters ......that coexist with local markets. In France, the home of the hypermarket, large-scale formats coexist with superettes and local markets, whereas in the UK and the Netherlands, fewer formats are evident, with superstores and supermarkets respectively dominating their markets".

${ }^{4}$ Igami (2011) provides empirical evidence of the the coexistence of different retail formats in the supermarket industry in Tokyo.
} 
both goods) or a single product retailer. Interestingly, we obtain an asymmetric equilibrium with one multi-product firm and one single product firm. In order to understand the result, suppose first that the two retailers are multiproduct firms. In this case, the two markets would be completely separated and each producer would optimally charge the monopoly wholesale price to each retailer. If one of the retailers decides to reduce its product assortment, becoming a single product firm, it will choose the manufacturer offering the lowest wholesale price. This leads the producers to compete for the single product retailer by reducing the wholesale prices (up to the point at which the profits of the manufacturer supplying to the two retailers are the same as the profits of the manufacturer supplying to only one retailer). Overall, the losses from selling only one good are more than compensated by the fall in the wholesale prices, such that becoming a single product retailer is profitable. Second, suppose now that both retailers are single product. In this case, no equilibrium exists in which both retailers choose the same supplier and so each retailer would end up selling a different good. But, in this situation, the manufacturers do not need to compete for the retailers and it turns out that the equilibrium wholesale prices would be again the monopoly wholesale prices. Therefore, the best response of any retailer to the rival retailer remaining single product would be to become multi-product, because as we have seen, mimicking the strategy of the rival would reduce the variety of goods sold without benefiting from a lower wholesale price.

Interestingly, we show that the social welfare maximizing scenario would be the one with two multiproduct retailers. Therefore, it turns out that in our setting, the strategic reduction of assortment by a retailer is detrimental for society. This is the result of two effects of different sign. On the one hand, the reduction of assortment reduces variety; on the other hand, it reduces the wholesale prices. As the former effect is larger than the latter effect as far as total welfare is concerned, the asymmetric retail formats equilibrium is welfare detrimental. 
Another interesting issue that we address in the paper is the role that horizontal mergers play in our setting. In particular, we analyze the profitability and welfare effects of both downstream and upstream mergers. With respect to a retailers' merger, we show that the merged entity would commit to carry only one good. In this way, competition between manufacturers to attract the unique retailer would reduce the wholesale prices to their marginal cost, which renders the merger profitable. As far as social welfare is concerned, there is a trade-off: on the one hand, the merger would have the positive effect of reducing the wholesale prices; on the other hand, the negative effect of reducing both competition and variety. It is direct to see that the negative effect dominates, so that a retailers' merger would reduce social welfare in our setting.

Concerning a manufacturers' merger, it would eliminate the retailers' incentives to reduce assortment: in absence of upstream competition, an assortment reduction by a retailer would imply a reduction in variety without any reduction in the intermediate prices. We show that, in this scenario, carrying two goods would be a dominant strategy for both retailers and the unique equilibrium of the game. Interestingly, the retailers face a prisoner's dilemma: both retailers would be better off if they could credibly commit to restrict assortment and sell only one good each because downstream competition would be lower in that case. Concerning social welfare, there is also a trade off: on the one hand, a manufacturers' merger prevents assortment reduction by retailers but, at the same time, by eliminating upstream competition, it avoids a reduction in the wholesale prices. We obtain that the positive effect on assortment dominates the negative effect on the wholesale prices such that an upstream merger increases social welfare in our setting.

In order to check the robustness of our results, we extend our main model into two different directions. We consider first an extension with linear contracts and no price discrimination and, second, a setting where retailers compete in prices. In both cases, asymmetric retailers in terms 
of product assortment are obtained. ${ }^{5}$

The rest of the paper is organized as follows. Next, we review the related literature. Section 3 analyzes the benchmark model. Section 4 is devoted to merger policy. In Section 5 , we extend the main model to the cases of no price discrimination in the intermediate markets and price competition. A final section concludes.

\section{Related literature}

The present paper contributes to the literature that studies the equilibrium determination of retail formats. Two of the latest contributions into this direction are Johansen and Nilssen (2016) and Rhodes and Zhou (2019). Although their approach is very different from ours (they both rely on consumers' preference for one-stop shopping), they also emphasize the possibility than, in equilibrium, firms with different product assortment coexist in the market. In particular, Rhodes and Zhou (2019) analyze the incentives of retailers selling different products to merge and sell them in one place, reducing consumers' search costs and providing them with one-stop shopping convenience. They show that when search costs are sufficiently low, the equilibrium market structure is asymmetric, with one multiproduct firm and two single product firms. On the other hand, Johansen and Nilssen (2016) also study retailers' incentives to merge in the presence of consumers with preferences for one-stop shopping, which creates complementarities between products in their setting and leads to lower prices after a big retailer is formed but may also lead to improve its bargaining position with respect to producers. The authors find that big stores are not formed when the retailers' ex ante bargaining power is already high. When it is not, they find that if one-stop shoppers are abundant, an asymmetric equilibrium exists with

\footnotetext{
${ }^{5}$ The case with price competition is special in that, due to the intensity of competition, the retailer that decides to carry two goods only sells units of the good which is not sold by the competitor.
} 
only one big retailer created.

Within the same branch of the literature, our paper is also related to Avenel and Caprice (2006), Dukes et al. (2009) and Cong Pan (2019). The former paper considers an upstream sector where two goods of different quality are produced and a retailing sector where two (undifferentiated) retailers compete à la Cournot. If the upstream sector is competitive, both retailers sell both qualities i.e. we have symmetric retail formats. However, if the high quality good is produced by a monopolist which is relatively inefficient, they obtain that retailers sell different qualities in equilibrium. Therefore, in their setting, it is upstream market power that may explain the presence of asymmetric retail formats downstream. Dukes et al. (2009), on the other hand, explain the existence of asymmetric retail formats as a consequence of the incentives of a powerful retailer to strategically reduce assortment depth in order to reduce assortment costs and gain a competitive advantage over competitors that carry more products. In contrast, in our paper, strategic assortment reduction arises from a desire to make manufacturers compete for the scarce shelf space, in order to get better deals in the intermediate market. This explains that, in contrast to Dukes et al. (2009), who analyze the case of one manufacturer and two retailers, we extend their setting to two manufacturers and two retailers. Cong Pan (2019) studies assortment decisions by a retailer that faces competition from the manufacturer's direct distribution channel. In this setting, the retailer may reduce assortment strategically to avoid competing with the manufacturer in the same product lines. ${ }^{6}$

Our paper is also connected with the literature on exclusive dealing with linear supply contracts (notice that in our model, when a retailer reduces its product assortment, it is in fact excluding one manufacturer). Within this literature, Mathewson and Winter (1987) focus on the effect of exclusive dealing chosen by producers, in a setting with two manufacturers and one

\footnotetext{
${ }^{6}$ See also Avignon et al. (2019), who analyze the impact of the formation of retailers' buying groups on product variety and profit sharing within a vertical chain with multi-product suppliers and capacity constrained retailers.
} 
retailer. They show that exclusive dealing arises in equilibrium only if the manufacturers are asymmetric enough. In a related paper, Gabrielsen and Sorgard (1999), using the same setting, study the retailer's incentives to require exclusivity. ${ }^{7}$ The retailer chooses to take only one good if the goods sold by the manufacturers are symmetric enough in terms of demand potential. If the goods are very asymmetric, the auction type situation induced by exclusivity does not constraint much the wholesale price set by producers and the retailer prefers to serve both goods. In the present paper, we consider a setting with symmetric demands. For our particular case, Gabrielsen and Sorgard (1999) obtain that the (unique) retailer always asks for exclusivity. With two retailers, we obtain instead that only one of the retailers asks for exclusivity. Therefore, comparing both papers, we could conclude that the incentives to ask for exclusivity decrease when we add a second retailer competing in the downstream market.

Following with the literature on exclusive dealing, we should also mention Mauleon et al. (2011) and Moner-Colonques et al. (2004), who study equilibrium distribution systems in a setting with two retailers. In both papers, for the case of independent goods, they find that there is no exclusion and both retailers sell both goods in equilibrium. Therefore, it seems that the way in which we model the interaction between suppliers and retailers, where retailers do not choose the products they want to carry but the number of goods they want to sell, increases the incentives for exclusion.

Further developments show that there exist equilibria without exclusion if more complex supply contracts are considered (see for example Miklós-Thal et al. (2011) and Rey and Whinston (2013)).

We next proceed to describe and solve the benchmark model.

\footnotetext{
${ }^{7}$ Similarly, Inderst and Shaffer (2007) study the advantage of single sourcing .i.e. the advantage to commit to sell only one good from the two that are available. Dana (2012) builds on a similar idea to show that buyer groups are profitable when their members are heterogeneous and commit to an exclusive purchase agreement.
} 


\section{Main model}

Assume we have two manufacturers ( 1 and 2 ) producing goods 1 and 2 respectively. For simplicity and as in Dukes et al. (2009), goods 1 and 2 are assumed to be independent. ${ }^{8}$ Demand for good i $(\mathrm{i}=1,2)$ is given by $P_{i}=a-Q_{i}$, where $P_{i}$ and $Q_{i}$ are respectively the price and the quantity sold of good i. Goods are to be sold through two retailers (1 and 2) that compete $\grave{a}$ la Cournot in the final goods market. Supply contracts are assumed to be linear and to simplify things and without loss of generality for our purpose, we assume that there are neither production nor retailing costs.

We study the following four stage game: in the first stage, retailers simultaneously and independently decide how many goods to carry. In the second stage, suppliers simultaneously and separately set the linear wholesale prices, that can be different for each retailer. In the third stage, the retailers that have chosen to carry only one good decide which good to sell. Finally, in the last stage, retailers decide how many units to buy from suppliers and how many units to sell in the market. ${ }^{9}$

We will obtain the subgame perfect Nash equilibrium of the proposed game, solving it by

\footnotetext{
${ }^{8}$ Given this assumption, the results of our model would seem to be only applicable to the choice of assortment breadth (number of product lines). However, we believe that the intuitions that explain our main result would also be valid for the choice of assortment depth (number of varieties within a product line). In Dukes et al. (2009) for example, even though the authors refer explicitly to the choice of assortment depth, they indeed consider independent goods and argue that the incentives to strategically reduce assortment would be reinforced in their setting when introducing the dimension of competition between varieties.

${ }^{9}$ It is the same order of moves as in Marx and Shaffer (2010), except that we add stage 3 to let retailers that have chosen to carry only one good to decide which one to sell. Another important difference is that they consider only one retailer and general contracts whereas we consider two retailers and linear supply contracts. Marx and Shaffer (2010) study a very different issue, namely, the role played by slotting allowances in retail markets and their (anti) competitive effects.
} 
backward induction.

In the last stage, we have Cournot competition. In the third stage, the retailer with reduced assortment will choose to sell the most profitable good. So we can go directly to solve the second stage of the game where, given the assortment decisions made by retailers in the first stage, the producers set the wholesale prices. We summarize the decision of the first stage with a vector, where the first (second) component stands for the number of goods that retailer 1 (2) decides to carry.

If the decision in the first stage amounts to $(2,2)$, i.e. both retailers decide to become multiproduct firms, the results of the game are well-known. In this case, the markets are completely separated. If $w_{i k}$ represents the wholesale price that producer i offers to retailer $\mathrm{k}$, we have that producer i chooses the wholesale prices to maximize:

$$
\underset{w_{i 1}, w_{i 2}}{\operatorname{Max}}\left[w_{i 1}\left(\frac{a-2 w_{i 1}+w_{i 2}}{3}\right)+w_{i 2}\left(\frac{a-2 w_{i 2}+w_{i 1}}{3}\right)\right]
$$

where the expressions in brackets are the equilibrium Cournot outputs of retailers 1 and 2 (and producer i's intermediate demands of good i) as a function of the wholesale prices charged by producer i to retailers 1 and 2 . It is straightforward to see that the optimal wholesale prices are $w_{i 1}^{22}=w_{i 2}^{22}=\frac{a}{2}$. Each producer gets $\Pi_{U}^{22}=\frac{a^{2}}{6}$ and each retailer, taken into account that they sell two goods, $\Pi_{R}^{22}=\frac{a^{2}}{18}$ (the proof is included in Appendix 3).

If retailer 2 decides not to carry any good, retailer 1 becomes a monopolist retailer (this scenario is similar to the one with a retailers' merger). If retailer 1 decides to carry only one good $(1,0)$, we have that competition between producers to be patronized by this retailer would drive the wholesale prices to zero. Therefore, we have that producers obtain zero profits and retailer 1 the monopoly profits in one market $\Pi_{R}^{10}=\frac{a^{2}}{4}$. On the other hand, if retailer 1 decides 
to carry two goods $(2,0)$, markets are completely separated. In this case, producer i maximizes:

$$
\underset{w_{i 1}}{\operatorname{Max}}\left[w_{i 1}\left(\frac{a-w_{i 1}}{2}\right)\right]
$$

The optimal wholesale price is $w_{i 1}^{20}=\frac{a}{2}$. Each manufacturer obtains $\Pi_{U}^{20}=\frac{a^{2}}{8}$ and retailer $1 \Pi_{R}^{20}=\frac{a^{2}}{8}$. An interesting implication of these results is that if retailers merge, they would optimally decide to reduce assortment, i.e. to carry only one good. Also the comparison between scenarios $(2,2)$ and $(2,0)$ shows that downstream competition, by reducing the double marginalization problem, increases upstream profits.

Next, we analyze the two remaining subgames: $(1,2)$ and $(1,1)$. In both cases, we have that both retailers are active but assortment has been reduced.

In the subgame $(1,2)$ we have that, by reducing assortment, retailer 1 achieves a reduction in the wholesale price. In equilibrium, we obtain $w_{11}=w_{21}=\frac{a}{4}$ and $w_{12}=w_{22}=\frac{a}{2}$ (see Appendix 1). Upstream firms offer the standard wholesale price $\frac{a}{2}$ to the retailer that offers two goods. Regarding the single product retailer, producers compete to be the one patronized by this firm by reducing the wholesale price. This process ends at $w=\frac{a}{4}$, namely, the wholesale price at which the upstream firm that serves the two retailers earns the same profit as the upstream firm that sells to only one retailer. The retailer that only sells one good gets $\Pi_{R}^{1}=\left(\frac{a}{3}\right)^{2}$ and the multiproduct retailer $\Pi_{R}^{2}=\left(\frac{a}{4}\right)^{2}+\left(\frac{a}{12}\right)^{2}$. Given that $\Pi_{R}^{1}>\Pi_{R}^{2}$, we conclude that specialized shops are more profitable than generalist shops. The reason is that in our setting, the introduction of additional product lines comes at the cost of higher wholesale prices.

The last subgame to be analyzed is the one in which both retailers have restricted their assortment $(1,1)$. In this scenario we have that, in equilibrium, each retailer sells a different good and they pay a wholesale price of $\frac{a}{2}$ (see Appendix 1). It is as if both markets were separated and producers distributed the goods through only one retailer. Each retailer gets $\Pi_{R}^{11}=\left(\frac{a}{4}\right)^{2}$. 
The following payoff matrix describes the game in the first stage. Although retailers can choose not to carry any good, this option has not been included in the matrix because it is a strictly dominated strategy.

\begin{tabular}{|l|l|l|}
\hline $1 \backslash 2$ & 2 & 1 \\
\hline 2 & $\frac{a^{2}}{18}, \frac{a^{2}}{18}$ & $\left(\frac{a}{4}\right)^{2}+\left(\frac{a}{12}\right)^{2},\left(\frac{a}{3}\right)^{2}$ \\
\hline 1 & $\left(\frac{a}{3}\right)^{2},\left(\frac{a}{4}\right)^{2}+\left(\frac{a}{12}\right)^{2}$ & $\left(\frac{a}{4}\right)^{2},\left(\frac{a}{4}\right)^{2}$ \\
\hline
\end{tabular}

Given the above payoffs matrix, it is direct to compute the first stage equilibrium, that we summarize in the following proposition:

Proposition 1 Under linear wholesale prices, we obtain asymmetric retail formats in equilibrium: one retailer decides to carry only one good and its rival prefers to carry the two goods.

Therefore, in equilibrium we find otherwise symmetric retailers offering different assortment breadth, which is consistent with what we observe in many retail markets. ${ }^{10}$ The intuition for the result is the following: first, suppose that the two retailers are multiproduct. In this case, the two markets would be completely separated and each producer would optimally charge the monopoly wholesale price to each retailer. Suppose now that one of the retailers decides to reduce its product assortment and become a single product firm. The producers will still charge the monopoly wholesale price to the multi-product retailer. As far as the single product retailer is concerned, this firm will decide to choose the manufacturer who offers its good at the lowest wholesale price. This leads the producers to compete to be the one patronized by the single

\footnotetext{
${ }^{10}$ Given that we assume that both retailers decide on assortment simultaneously, we obtain two asymmetric equilibria in the first stage of the proposed game. We could of course select anyone of these equilibria by just assuming that one of the retailers is dominant in the market and has the capacity to choose the number of goods to carry in advance, as a leader (this assumption would be similar to the one used in Dukes et al. (2009). The leader would then choose to reduce assortment and the follower would be a multiproduct firm, carrying two goods.
} 
product retailer by reducing the wholesale prices up to the point at which the profits of the manufacturer supplying to the two retailers are the same as the profits of the manufacturer supplying to only one retailer. In equilibrium, it turns out that the reduction in the wholesale price is so important, that becoming a single product retailer is profitable. The losses from selling only one good are more than compensated by the fact the that the wholesale price that the single product retailer pays is much lower than the monopoly wholesale price that it would pay when carrying the two goods. Second, suppose now that both retailers are single product. In this case, no equilibrium exists in which both retailers choose the same supplier, which would exclude the other supplier from the market. The reason is that, given that the goods are independent, the excluded supplier could always find a suitable reduced wholesale price to attract one of the retailers. Then, in the market configuration with two single product retailers, each retailer would end up selling a different good. But, in this situation, it turns out that the equilibrium wholesale prices would be again the monopoly wholesale prices. Therefore, the best response of any retailer to the rival retailer remaining single product would be to become multi-product, because as we have seen, mimicking the strategy of the rival would reduce the variety of goods sold without benefiting from a lower wholesale price.

Apart from obtaining asymmetric retail formats in equilibrium, we have seen that the specialized retailer obtains more profits than the multi-product retailer. Despite offering a narrower product breadth, the specialized shop is able to reach a higher profitability, because it obtains lower wholesale prices by making suppliers compete against each other. This advantage in terms of wholesale prices may help to explain that the "old model" of multi-product retailers seems to be less profitable nowadays. This may also explain the success of hard discounters, as Aldi or Lidl, that offer a narrower assortment than supermarkets. ${ }^{11}$ However, as we will see in Sec-

\footnotetext{
${ }^{11}$ [Hard-discounters] "offer much fewer categories of goods, and stock a limited selection of items-typically fewer that 1.400 stock-keeping units (SKUs), compared to the $15000+$ items carried in most supermarkets or the
} 
tion 5.1., this result on profitability may be reversed when non-discriminatory tariffs apply in the intermediate market. Therefore, our results suggest that whether specialized or generalist shops are more profitable may, at the end of the day, depend on the regulatory context in the intermediate market.

Concerning social welfare, it is easy to show (see Appendix 3) that it is maximized in the scenario with two multiproduct retailers. Therefore, it turns out that the strategic reduction of assortment is detrimental for society. This is the result of two opposing effects. On the one hand, the reduction of assortment reduces variety; on the other hand, it leads to a wholesale prices cut. As the former effect is larger than the latter as far as total welfare is concerned, the asymmetric retail formats equilibrium is welfare detrimental.

\section{Merger policy}

At this point, it seems interesting to analyze whether and how the retailers' strategic incentives to reduce assortment, that we have identified in our benchmark model, are affected by either a retailers' merger or a manufacturers' merger. More generally, we aim to study the profitability and welfare effects of such mergers with the aim to derive the optimal merger policy.

As we have already mentioned, if the retailers decided to merge, they would decide to commit to carry only one good. In this way, competition between suppliers to be patronized by the unique retailer would drive the wholesale prices to zero. The merged firm would get $\left(\frac{a}{2}\right)^{2}$, which is higher than the joint profits of the merged firms pre-merger i.e. the merger is profitable. As far as social welfare is concerned, there is a trade-off: on the one hand, the merger has the positive effect of reducing the wholesale prices; on the other hand, it has the negative effect of reducing both competition and variety. It is direct to see (see Appendix 3) that the negative $80.000+$ items in a WalMart supercenter." (Cleeren et al. (2010) p.456.) 
effect dominates, resulting in a welfare detrimental merger.

Next, we study the case in which suppliers merge and retailers remain independent. In this case, as the merger eliminates competition upstream, the monopoly producer would charge wholesale prices $w_{11}=w_{12}=w_{21}=w_{22}=\frac{a}{2}$ in all the scenarios. ${ }^{12}$ But this implies that the retailers' incentives to reduce assortment no longer exist: with an upstream monopoly, an assortment reduction by retailers implies a reduction in variety without any reduction in the intermediate prices. Next, we present the payoff matrix of the assortment game played by the retailers under upstream monopolization. Observe that in scenario $(1,1)$, given the wholesale prices, the retailers would decide to sell different goods.

\begin{tabular}{|l|l|l|}
\hline $1 \backslash 2$ & 2 & 1 \\
\hline 2 & $\frac{a^{2}}{18}, \frac{a^{2}}{18}$ & $\frac{a^{2}}{36}+\frac{a^{2}}{16}, \frac{a^{2}}{36}$ \\
\hline 1 & $\frac{a^{2}}{36}, \frac{a^{2}}{36}+\frac{a^{2}}{16}$ & $\frac{a^{2}}{16}, \frac{a^{2}}{16}$ \\
\hline
\end{tabular}

It is direct to see that carrying two goods is a dominant strategy for both retailers and the unique equilibrium of the game, i.e. independent retailers in this setting would not restrict product assortment. It is a prisoner's dilemma situation because both retailers would obtain more profits if they could credibly commit to restrict assortment and sell only one good each, as downstream competition would be lower in that case. Moner-Colonques et al. (2011) also show that, if demands are not very asymmetric, retailers would choose to carry overlapping product

\footnotetext{
${ }^{12}$ The only case where this result is not obvious is in scenario $(1,1)$. In this subgame, we should compare the profits of the upstream firm when each retailer sells a different good and when both retailers sell the same good, such that competition between retailers reduces the double marginalization problem. In the former case, the optimal wholesale prices are $w_{11}=w_{12}=w_{21}=w_{22}=\frac{a}{2}$. With these wholesale prices, retailers will decide to sell different goods and the upstream firm would obtain $2\left(\frac{a-\frac{a}{2}}{2}\right) \frac{a}{2}=\frac{a^{2}}{4}$. In the latter case, the optimal wholesale prices are, for example, $w_{11}=w_{12}=a$ and $w_{21}=w_{22}=\frac{a}{2}$ and the upstream firm would obtain, in this case, $2\left(\frac{a-\frac{a}{2}}{3}\right) \frac{a}{2}=\frac{a^{2}}{6}$. Therefore, the upstream firm is better off when each retailer sells a different good i.e. with wholesale prices $w_{11}=w_{12}=w_{21}=w_{22}=\frac{a}{2}$.
} 
lines.

In this setting with a monopolist manufacturer, if retailers merge, they would not restrict assortment, as this strategy would not affect the wholesale prices, that are set by the upstream firm equal to $\frac{a}{2}$ in any case. The merger would have the only effect of reducing competition, which explains that it would increase firms' profits and reduce total welfare.

Now we turn our attention to the effect of an upstream merger on total welfare. Given that a retailers' merger reduces welfare both under upstream competition and upstream monopoly, we can focus on the effects of an upstream merger when we have independent retailers. On the one hand, it has the negative effect, common in many papers, of (weakly) increasing the wholesale prices (see, for example, Horn and Wolinsky (1988), Iozzi and Valetti (2014) and Milliou and Sandonís (2018). On the other hand, in the present paper a new positive effect of an upstream merger arises, namely, that it prevents the restriction of assortment by retailers, which would otherwise reduce competition and variety. Interestingly, we obtain that the positive effect on assortment dominates the negative effect on wholesale prices such that an upstream merger increases social welfare in our setting. From a policy perspective, it is important to notice that upstream mergers and downstream mergers thus lead to very contrasted results in terms of total welfare when product assortment choice by retailers is taken into account: while a retailers' merger results in lower total welfare, we have shown that total welfare increases when a manufacturers' merger occurs. Next proposition summarizes the optimal merger policy in our setting.

Proposition 2 The welfare maximizing merger policy should forbid a retailers' merger and should approve a manufacturers' merger.

Notice that the result that a manufacturers' merger is welfare improving in our framework is in contrast with the result in Milliou and Sandonis (2018), where it is shown that a manufac- 
turers' merger is anticompetitive. The reason for this negative result in Milliou and Sandonís (2018) is that in their setting, the manufacturers decide not only the wholesale prices but also how many varieties to produce, that is, manufacturers keep the complete channel power. They show that even in the cases in which a manufacturers' merger increases variety, this is not enough to compensate the anticompetitive effects of the higher wholesale prices set after the merger. In the present paper however, where the channel power has shifted from the manufacturers to the retailers, a manufacturers' merger, by eliminating upstream competition, reduces the retailers incentives to restrict product assortment, which explains our result.

\section{EXTENSIONS}

\subsection{No price discrimination in the intermediate markets}

In the previous section, producers were allowed to charge different wholesale prices to retailers. It seems interesting also to analyze a situation in which the competition authorities forbid price discrimination in the input markets. ${ }^{13}$ Notice that, with no price discrimination allowed, a retailer may be less interested in reducing its product assortment because it knows that any reduction in the wholesale price has to be shared with the competing retailer.

In the subgame where no retailer has reduced assortment, namely, subgame $(2,2)$, the equilibrium of the previous section involved no price discrimination. Therefore, forbidding price discrimination does not change the equilibrium.

In the subgame where both retailers have reduced their assortment, scenario $(1,1)$, in the previous section we found an equilibrium without price discrimination $w_{11}=w_{21}=w_{12}=$ $w_{22}=\frac{a}{2}$. It should also be an equilibrium now, because forbidding price discrimination can not increase the profits of deviations. In order for a producer to be able to supply to both retailers,

\footnotetext{
${ }^{13}$ For example, the Robinson-Patman Act 1936, forbade price discrimination in the input market.
} 
it should be willing to reduce its wholesale price to $\frac{a}{4}$, but this deviation does not increase its payoff. Therefore, forbidding price discrimination will not change the equilibrium payoffs in this case either.

Things change dramatically when only one retailer, say 1 , has reduced its assortment, that is, subgame $(1,2)$ for example. In this case, producers have to compete for the capacity of retailer 1 , without the ability to grant this firm particular discounts. The situation is similar to Varian (1980), where firms face both locked-in and informed consumers. As in this case, no pure strategy equilibrium exists in the pricing stage. Let us elaborate more on this issue. Suppose, for example, that upstream firm 2 sells only to retailer 2. In this case, it will optimally make profits $\frac{a^{2}}{8}$ by setting a wholesale price $\frac{a}{2}$. Clearly, a firm will never make lower profits in any equilibrium. Upstream firm 1 setting a wholesale price $\frac{a}{2}-\varepsilon$ is not an equilibrium because upstream firm 2 would have an incentive to undercut its rival in order to sell to retailer 1 also, unless upstream firm 1 sets a wholesale price $w_{1}<\frac{a}{2}$ such that $2 w_{1}\left(\frac{a-w_{1}}{3}\right)=\frac{a^{2}}{8}$, that is, such that both firms make the same profit (though at different wholesale prices) and upstream firm 2 has no incentives to undercut. Solving for $w_{1}$ the previous equation we get $w_{1}=\frac{a}{4}$. However, the pair of wholesale prices $\left(\frac{a}{4}, \frac{a}{2}\right)$ is not an equilibrium either, because upstream firm 1 would have an incentive to increase its wholesale price up to $\frac{a}{2}-\varepsilon$, so that it still sells its good to retailer 1 but gets more profits.

Although there is no pure strategy equilibrium as we have seen, it is easy to characterize a symmetric mixed strategy equilibrium. The next lemma describes such equilibrium.

Lemma 1 Under no price discrimination, when only one retailer has reduced its assortment, producers randomize their wholesale prices in equilibrium according to the following distribution function: 


$$
F(w)=\left\{\begin{array}{cl}
0 & \text { if } w<\frac{a}{4} \\
4+\frac{3 a^{2}}{4 w^{2}-4 a w} & \text { if } \frac{a}{4} \leq w<\frac{a}{2} \\
1 & \text { if } w \geq \frac{a}{2}
\end{array}\right.
$$

First, concerning the support of the distribution, it is very intuitive that the equilibrium support is given by $\left[\frac{a}{4}, \frac{a}{2}\right]$. The reason is that in a mixed strategy equilibrium, the expected profits of the upstream firms must be constant at any wholesale price in the support. Therefore, the upper bound of the support cannot be above $\frac{a}{2}$ because, no matter the wholesale price chosen by the rival, any upstream firm could get more profits by setting a wholesale price $\frac{a}{2}$. Similarly, the lower bound of the support cannot be below $\frac{a}{4}$ because, no matter the wholesale price chosen by the rival, any upstream firm could get more profits by setting a wholesale price $\frac{a}{2}$. Second, concerning the equilibrium distribution function, we can derive it by imposing the constant expected profit condition for any wholesale price in the support and taking into account that the expected profits must be equal to $\frac{a^{2}}{8}$. Formally, we have to impose:

$$
F(w) w\left(\frac{a-w}{2}\right)+(1-F(w)) 2 w\left(\frac{a-w}{3}\right)=\frac{a^{2}}{8}
$$

Solving for $F(w)$, we obtain the above equilibrium distribution function.

In order to be able to solve the first stage of the game, we still have to calculate the expected profits obtained by retailers when only retailer 1 reduces assortment, that is, the subgame $(1,2)$. We assume that the wholesale prices are realized at the beginning of stage 3 . In stage 3, retailer 1 will choose to sell the good whose wholesale price is lower. Then, it will pay the minimum of the two wholesale prices and we know that the distribution of the minimum is given by $1-(1-F(w))^{2}$. Retailer 2 will sell as a monopolist the good whose wholesale price is higher. Then, it will pay the maximum of the two wholesale prices and we know that the distribution of the maximum is given by $(F(w))^{2}$. Taking this into account, the expected profits of the retailers 
are given respectively by:

$$
\begin{aligned}
E R_{1} & =\int_{a / 4}^{a / 2} \frac{\partial\left(1-(1-F(w))^{2}\right)}{\partial w}\left(\frac{a-w}{3}\right)^{2} d w=\frac{a^{2}}{8}(\log [256 / 3]-4)>\frac{a^{2}}{18} \text { and } \\
E R_{2} & =\int_{a / 4}^{a / 2} \frac{\partial\left(1-(1-F(w))^{2}\right)}{\partial w}\left(\frac{a-w}{3}\right)^{2} d w+\int_{a / 4}^{a / 2} \frac{\left.\partial(F(w))^{2}\right)}{\partial w}\left(\frac{a-w}{2}\right)^{2} d w= \\
& =\frac{a^{2}}{32}\left(44+\log \left[243 / 4^{32}\right]\right)>\frac{a^{2}}{16} .
\end{aligned}
$$

Given the above computations, the payoff matrix of the game played in Stage 1 is the following:

\begin{tabular}{|l|l|l|}
\hline $1 \backslash 2$ & 2 & 1 \\
\hline 2 & $\frac{a^{2}}{18}, \frac{a^{2}}{18}$ & $\frac{a^{2}}{32}\left(44+\log \left[243 / 4^{32}\right]\right), \frac{a^{2}}{8}(\log [256 / 3]-4)$ \\
\hline 1 & $\frac{a^{2}}{8}(\log [256 / 3]-4), \frac{a^{2}}{32}\left(44+\log \left[243 / 4^{32}\right]\right)$ & $\frac{a^{2}}{16}, \frac{a^{2}}{16}$ \\
\hline
\end{tabular}

It is direct to compute the first stage equilibrium, that we summarize in the following proposition.

Proposition 3 Under no price discrimination, in equilibrium we still have an asymmetric outcome: one retailer decides to carry only one good and its competitor prefers to carry the two goods.

An important difference with respect to the case of price discrimination of the previous section is that now, given that price discrimination is not allowed, the specialized firm earns less profits than the generalist retailer. The reduction in the wholesale prices obtained by restricting assortment is so important however, that it is the optimal strategy, even though the price cuts have to be shared with the competitor. Notice that the expected minimum wholesale price is $0.292 a$ and the expected maximum price is $0.355 a$. They are much lower than $\frac{a}{2}$, the wholesale price retailers would pay in the subgames $(2,2)$ and $(1,1)$.

The next thing we have to check is the effect of a retailers' merger on social welfare and profits in this setting without price discrimination. The situation under a merger is like the 
one we had with price discrimination: the merged entity will choose to restrict assortment in order to drive the wholesale prices to zero. Social welfare in this case is $\frac{3 a^{2}}{8}$ and the profits of the merged retailer $\left(\frac{a}{2}\right)^{2}$ (see Appendix 3). With independent retailers, in equilibrium only one retailer restricts assortment. In this case, the expected profits of retailers are lower than $\left(\frac{a}{2}\right)^{2}$ and, therefore, the merger is profitable. Concerning the competitive effects of a retailers' merger, we can see the expected social welfare with independent retailers is given by the following expression, where $K(X)$ stands for social welfare if total sales amount to $X$ :

$\int_{a / 4}^{a / 2} \frac{\partial\left(1-(1-F(w))^{2}\right)}{\partial w} K\left(\frac{2(a-w)}{3}\right) d w+\int_{a / 4}^{a / 2} \frac{\left.\partial(F(w))^{2}\right)}{\partial w} K\left(\frac{a-w}{2}\right) d w=\frac{a^{2}}{64}\left(68-\log \left[2^{32} 243\right]\right)>\frac{3 a^{2}}{8}$.

Therefore, it turns out that a retailers' merger is profitable and reduces social welfare.

\subsection{Price competition downstream}

In this Section, we extend our benchmark model to consider the case in which retailers compete in prices, that is, competition between retailers becomes more intense. As usual, we assume that when two retailers set the same price for the same good, it is the retailer with the lowest wholesale price that gets all the demand. On the other hand, if both retailers face the same wholesale price and set the same final price, they are assumed to share demand equally.

Notice to start that in the subgames in which the retailers do not compete, the equilibrium will be as the one we obtained in Section 3. These are subgames $(0,1),(1,0),(2,0)$ and $(0,2)$. Thus, we have to analyze only the remaining possible scenarios, $(2,2),(1,2),(2,1)$ and $(1,1)$ in which retailers do compete.

Subgame $(2,2)$ is the one in which the difference between quantity competition and price competition is most remarkable. With two retailers and price competition, double marginalization is not an issue: upstream firms set the monopoly wholesale price $\left(\frac{a}{2}\right)$ and Bertrand competition between retailers leads both firms to set prices equal to $\frac{a}{2}$. Therefore, upstream firms are able 
to extract the full monopoly profits in this case.

In subgame $(1,1)$, we have the same situation that we had in Section 3. Each retailer sells a different good and they pay a wholesale price equal to $\frac{a}{2}$ (see Appendix 2). It is like if both markets were separated and producers distributed the goods through only one retailer.

Subgame $(1,2)$ is the most interesting case because retailer 1 , by restricting assortment, obtains a reduction in the wholesale price. Equilibrium wholesale prices are given by: $w_{11}=$ $w_{21}=\frac{a}{4}$ and $w_{12}=w_{22}=\frac{a}{2}$ (see Appendix 2). Upstream firms offer a standard wholesale price $\frac{a}{2}$ to retailer 2 and they compete for retailer 1 by lowering the wholesale prices. The process stops at $w=\frac{a}{4}$, when the supplier chosen by retailer 1 earns exactly the same profit than the rival supplier. Given that retailer 1 faces a lower wholesale price than retailer 2, the latter firm does not sell any quantity of the good sold by retailer 1 . Therefore, although retailer 2 has the physical capacity to sell two goods, it only sells a positive quantity of the good not sold by retailer 1 . As a consequence, retailer 2 obtains the same profit in $(1,2)$ as in $(1,1)$. In both cases, it is the only seller of a good with a wholesale price equal to $\frac{a}{2}$.

The assortment game played by retailers 1 and 2 in the first stage is represented by the following payoff matrix.

\begin{tabular}{|l|l|l|}
\hline $1 \backslash 2$ & 2 & 1 \\
\hline 2 & 0,0 & $\frac{a^{2}}{16}, \frac{a^{2}}{8}$ \\
\hline 1 & $\frac{a^{2}}{8}, \frac{a^{2}}{16}$ & $\frac{a^{2}}{16}, \frac{a^{2}}{16}$ \\
\hline
\end{tabular}

It is direct to see that there exist three equilibria: $(1,2),(2,1)$ and $(1,1)$. The first two equilibria correspond to the ones obtained when retailers compete in quantities. Under price competition, however, $(1,1)$ is also an equilibrium: carrying an additional good does not increase a retailer's profits because it would pay the same wholesale price and would make identical sales. Recall that, in the subgame $(1,2)$, retailer 2 only sells in equilibrium the good not sold by retailer 
1. However, if we refine the equilibria using Pareto-dominance (for the retailers), only equilibria $(1,2)$ and $(2,1)$ survive. Next Proposition summarizes this result.

Proposition 4 When retailers compete in prices, the Pareto undominated equilibria of the assortment game for the retailers are asymmetric, with one multiproduct and one single product retailer.

As a corollary of the previous result we can argue that the central result of our paper, namely, explaining the coexistence of different retail formats in terms of product assortment, seems to be robust with respect to the type of market competition being Cournot or Bertrand.

A final step in this section would be again to evaluate the welfare consequences of a retailers' merger. Not surprisingly, we find the same result than under quantity competition. Regardless of the equilibrium played without the merger, it turns out that a retailers' merger is profitable and reduces social welfare (see Appendix 3).

\section{Conclusions}

In this paper, we have studied the incentives of powerful retailers to reduce product assortment as a way to shape the retailers' interaction with suppliers. In particular, by reducing assortment, a retailer fosters competition between manufacturers for the scarce shelf space, which shifts bargaining power to the retailer, resulting into better deals in the intermediate market and so larger retailer's profits. In this way, we have shown that otherwise symmetric retailers may end up carrying different assortments, which is consistent with the well documented coexistence of different retail formats in many real retail markets. Interestingly, the incentives to reduce assortment are lower in a setting with two retailers competing in the downstream market than in a setting with a monopolist retailer. As a result, one important consequence of a retailers' 
merger in our setting is that it reduces the variety of goods available to consumers. This effect should be taken into consideration when evaluating the welfare consequences of mergers.

We have considered a model with two goods and two retailers. Both goods are sold when we have a duopoly in the retailing sector. When the retailers merge, however, the merged entity optimally decides to sell only one of the goods. If in order to approve the merger the antitrust authority imposes that both goods have to be sold, the merger would become unprofitable. Therefore, it is the ability to de-list one of the goods they were selling before the merger what renders the merger profitable. De-listing increases competition between suppliers and reduces the wholesale prices. Nevertheless, even if the antitrust authority imposes that no de-listing may take place after a merger, the merger would reduce welfare because of its negative effect on competition.

When studying the consequences of retailers' mergers, the literature has mainly focused on their effects on final prices (see Argentesi et al. (2016) for an exception) ignoring their possible effects on other non-price variables. The present paper shows that knowing the evolution of prices may not be enough to predict the evolution of welfare. Indeed, in our model a retailers' merger reduces the price. The merged entity obtains a reduction in the wholesale price that translates into a lower final price of the good it sells. However, this reduction in the wholesale price is obtained precisely by restricting product assortment, committing in this way to sell only one of the goods. Therefore, after the merger only one good is available to consumers, whereas two goods were available in duopoly. It turns out that the negative effect on variety is stronger than the positive effect on prices so that the merger reduces welfare.

Although the benchmark model considers that retailers compete à la Cournot, most results still hold when retailers compete à la Bertrand. In particular, the result that only one of the retailers restrict assortment in an asymmetric equilibrium in duopoly and that a retailers' merger 
reduces welfare. However, as competition is more intense under price competition, social welfare is higher in duopoly when retailers compete à la Bertrand than when they compete à la Cournot. Therefore, the welfare loss produced by the merger is higher under price competition.

In order to model the well documented empirical fact that the channel power has increasingly shifted from manufacturers to retailers, we have assumed along the paper that retailers have the power to commit to their product assortment but still, the supply contracts are set by suppliers. It seems interesting to discuss the consequences of assuming that retailers have also some bargaining power to negotiate the wholesale prices, as it seems to be the case in many retail markets. ${ }^{14}$ This could be done in the context of our model by modifying stage two. We could assume that after the product assortment choices are made, supply contracts are chosen by suppliers with probability $\lambda$ and by retailers with probability $1-\lambda$. Therefore, in this setting, the higher $\lambda$, the higher the bargaining power of suppliers and we could analyze how the assortment choices depend on $\lambda$. It is very intuitive that it would be in the interest of the retailers to restrict assortment whenever $\lambda$ is high enough. This would resemble a result in Inderst and Shaffer (2007), where single sourcing is the optimal strategy for retailers if the bargaining power of manufacturers is high enough.

All the analysis in this paper has relied on the assumption of linear supply contracts. A natural extension would be to consider non-linear supply contracts as, for example, two-part tariffs. The important difference between the two cases is that under linear contracts, producers value retailers competition because it reduces the double marginalization problem. This is not the case with two part-tariff contracts as, in this case, a producer would obtain the same profits with either one or two retailers. So we expect that there would be less competition among suppliers to be patronized by retailers under two-part tariff contracts than under linear contracts.

\footnotetext{
${ }^{14}$ For example, Fishman (2006) reports that dominant retailers (most notably Walmart) are also known to use their power to negotiate more strongly on wholesale price and delivery terms.
} 
And this could lead to significantly different results in terms of the assortment decisions taken by retailers. The formal analysis of bargaining power and the introduction of more complex contracts in our setting are left for future research. ${ }^{15}$

\section{Appendix}

\subsection{Appendix 1 (competition in quantities)}

The subgame $(1,2)$.

Proposition $5 w_{11}=w_{21}=\frac{a}{4}$ and $w_{12}=w_{22}=\frac{a}{2}$ are the equilibrium wholesale prices in the subgame (1,2).

Upstream firm i can always obtain $\frac{a^{2}}{8}$ by choosing $w_{i 1}=a$ and $w_{i 2}=\frac{a}{2}$. If in equilibrium upstream firm $\mathrm{i}$ is not chosen by retailer 1 , we have $w_{i 2}=\frac{a}{2}$. Then, we obtain the optimal wholesale prices of upstream firm $j$ if it sells to 1 , given $w_{i 1}$ and $w_{i 2}=\frac{a}{2}$. We assume that, in case of indifference, retailer 1 chooses upstream $j$. Upstream $j$ solves the following maximization program, where it maximizes its profits subject to the constraint that retailer 1 prefers to choose upstream firm j rather than upstream firm i:

$$
\begin{aligned}
& \underset{w_{j 1}, w_{j 2}}{\operatorname{Max}} f\left(w_{j 1}, w_{j 2}\right)=w_{j 1}\left(\frac{a-2 w_{j 1}+w_{j 2}}{3}\right)+w_{j 2}\left(\frac{a-2 w_{j 2}+w_{j 1}}{3}\right) \\
& \text { s.t. }\left(\frac{a-2 w_{j 1}+w_{j 2}}{3}\right)^{2} \geq\left(\frac{a-2 w_{i 1}+\frac{a}{2}}{3}\right)^{2} \\
& w_{j 1}, w_{j 2} \geq 0
\end{aligned}
$$

\footnotetext{
${ }^{15}$ For an analysis of multilateral interlocking relationships, allowing for any distribution of bargaining power and complex (secret) contracts see Rey and Vergé (2019).
} 
The maximization problem can be simplified and rewritten as:

$$
\begin{aligned}
& \underset{w_{j 1}, w_{j 2}}{\operatorname{Max}} f\left(w_{j 1}, w_{j 2}\right)=w_{j 1}\left(\frac{a-2 w_{j 1}+w_{j 2}}{3}\right)+w_{j 2}\left(\frac{a-2 w_{j 2}+w_{j 1}}{3}\right) \\
& \text { s.t. }-\left(a-2 w_{i 1}+\frac{a}{2}\right) \geq-\left(a-2 w_{j 1}+w_{j 2}\right) \\
& w_{j 1}, w_{j 2} \geq 0
\end{aligned}
$$

We can now write the Lagrangian function Z:

$$
Z=f\left(w_{i 1}, w i_{2}\right)+\lambda\left(-\left(a-2 w_{i 1}+\frac{a}{2}\right)+a-2 w_{j 1}+w_{j 2}\right)
$$

Then, the Kuhn-Tucker conditions are given by $(k=1,2)$ :

$$
\begin{aligned}
\frac{\partial Z}{\partial w_{j k}} \leq 0 & w_{j k} \geq 0 \text { and } w_{j k} \frac{\partial Z}{\partial w_{j k}}=0 \\
\frac{\partial Z}{\partial \lambda} \geq 0 & \lambda \geq 0 \text { and } \lambda \frac{\partial Z}{\partial \lambda}=0 .
\end{aligned}
$$

Then, we have to find values for the wholesale prices and the Lagrange multiplier that satisfy these conditions. Asssume that the solution is such that wholesale prices are positive, then $\frac{\partial Z}{\partial w_{j k}}=0$. We solve the system of equations formed by:

$$
\frac{\partial Z}{\partial w_{j 1}}=0, \frac{\partial Z}{\partial w_{j 2}}=0 \text { and } \lambda \frac{\partial Z}{\partial \lambda}=0
$$

We obtain two solutions:

$$
\begin{aligned}
& w_{j 1}=w_{j 2}=\frac{a}{2} \text { and } \lambda=0 \\
& w_{j 1}=w_{i 1}, w_{j 2}=\frac{a}{2} \text { and } \lambda=\frac{a-2 w_{i 1}}{3} .
\end{aligned}
$$

The first one satisfies $\frac{\partial Z}{\partial \lambda} \geq 0$ only if $w_{i 1} \geq \frac{a}{2}$ and the second one satisfies $\lambda \geq 0$ only if $w_{i 1} \leq \frac{a}{2}$. Both solutions coincide if $w_{i 1}=\frac{a}{2}$. Summarizing, the optimal wholesale prices for firm $j$ are $w_{j 1}=w_{j 2}=\frac{a}{2}$ if $w_{i 1}>\frac{a}{2}$ and $w_{j 1}=w_{i 1}, w_{j 2}=\frac{a}{2}$ if $w_{i 1} \leq \frac{a}{2}$. 
So, in equilibrium, both upstream firms will charge $\frac{a}{2}$ to retailer $2\left(w_{12}=w_{22}=\frac{a}{2}\right)$ and the same wholesale price $w$ to retailer $1\left(w_{11}=w_{21}=w\right)$. To obtain the equilibrium value of $w$, we have to impose the condition that the producer supplying to two retailers obtains the same profit as the producer supplying to only one retailer i.e.:

$$
w\left(\frac{a-2 w+\frac{a}{2}}{3}\right)+\left(\frac{a}{2}\right)\left(\frac{a-2\left(\frac{a}{2}\right)+w}{3}\right)=\frac{a^{2}}{8}
$$

This equation has two solutions $w=\frac{a}{4}$ and $w=\frac{3 a}{4}$. We can disregard the second solution because the upstream firms would have incentives to lower the wholesale price to $\frac{a}{2}$. Then, in equilibrium, we have that $w_{11}=w_{21}=\frac{a}{4}$ and $w_{12}=w_{22}=\frac{a}{2}$.

The subgame $(1,1)$.

Proposition 6 In the subgame (1,1), each supplier sells to a different retailer at a wholesale price equal to $\frac{a}{2}$.

The claim is is proved throught the following 3 Lemmata:

Lemma 2 There is no equilibrium in which both retailers choose the same supplier.

If supplier $j$ is chosen by both retailers, then the wholesale prices chosen by $j$ should be lower than the ones chosen by $i$. Nevertheless, we can see that this cannot be an equilibrium, because $i$ has a profitable deviation. We distinguish two cases depending on whether $j$ sets the same wholesale prices to both retailers (Case 1) or not (Case 2).

Case 1:

$$
a>w_{i 1} \geq w_{i 2}>w_{j 1}=w_{j 2} \geq 0 .
$$

This cannot be an equilibrium because $i$ has a profitable deviation, namely $w_{i 2}=a$ and $w_{i 1}=$ $w_{j 1}+\varepsilon$, where $0<\varepsilon<\frac{a-w_{j 1}}{3}$. In this case, retailer 2 chooses supplier $j$ and retailer 1 chooses supplier $i$, because

$$
\frac{a-w_{j 1}-\varepsilon}{2}>\frac{a-w_{j 1}}{3}
$$


Then, supplier i makes positive profits and the deviation is profitable.

Case 2:

$$
a>w_{i 1} \geq w_{i 2}>w_{j 1}>w_{j 2} \geq 0 .
$$

This cannot be an equilibrium because $i$ has a profitable deviation, namely $w_{i 2}=a$ and $w_{i 1}=$ $w_{j 1}$. In this case, retailer 2 chooses supplier $j$ and retailer 1 chooses supplier $i$, because

$$
\frac{a-w_{j 1}}{2}>\frac{a-2 w_{j 1}+w_{j 2}}{3}
$$

Then, supplier $i$ makes positive profits and the deviation is profitable.

Lemma 3 There is no equilibrium in which the suppliers sell the good to retailers at a wholesale price different from $\frac{a}{2}$.

For Lemma 2, it should be the case that each retailer chooses a different upstream firm and makes positive sales. We first show (by contradiction) that the equilibrium wholesale prices paid by the retailers cannot be below $\frac{a}{2}$.

Consider an equilibrium vector of wholesale prices, with matches $(k, i)$ and $(l, j)$ and $w_{i k} \leq$ $w_{j l}<\frac{a}{2}$. This yields profits of $w_{i k}\left(\frac{a-w_{i k}}{2}\right)$ to upstream firm $i$. We show next that upstream firm $i$ has a profitable deviation. We distinguish two cases: (i) $a-2 w_{j k}+w_{j l}>0$ and (ii) $a-2 w_{j k}+w_{j l} \leq 0$.

In case (i), let us consider a deviation by firm $i$ to $w_{i k}^{\prime}=a$ and $w_{i l}^{\prime}=w_{j l}+\varepsilon$, where $0<\varepsilon<\min \left\{\frac{a}{2}-w_{j l}, \frac{a-2 w_{j k}+w_{j l}}{3}\right\}$. In this subgame, retailer $k$ would choose upstream firm $j$ (dominant strategy) and, therefore, retailer $l$ would match with firm $i$, because

$$
\left(\frac{a-w_{i l}^{\prime}}{2}\right)^{2}>\left(\frac{a-w_{j l}-\left(\frac{a-2 w_{j k}+w_{j l}}{3}\right)}{2}\right)^{2}=\left(\frac{a-2 w_{j l}+w_{j k}}{3}\right)^{2} .
$$

As a consequence, $w_{i l}^{\prime}\left(\frac{a-w_{i l}^{\prime}}{2}\right)>w_{i k}\left(\frac{a-w_{i k}}{2}\right)$ and the deviation is profitable. 
In case (ii), upstream firm $i$ could increase its payoff by setting $w_{i k}^{\prime}=\frac{a}{2}$ and $w_{i l}^{\prime}=a$. In this case, retailer $l$ will still match with upstream firm $j$ and retailer $k$ with upstream firm $i$, because it would obtain zero profit by choosing $j$. Therefore, the profits of the upstream firm $i$ would be $\frac{a^{2}}{8}>w_{i k}\left(\frac{a-w_{i k}}{2}\right)$.

Second, we show that the equilibrium wholesale prices can not be above $\frac{a}{2}$. Let consider an equilibrium vector of wholesale prices, with matches $(k, i)$ and $(l, j)$ and $w_{i k}>\frac{a}{2}$. This implies that

$$
\left(\frac{a-w_{i k}}{2}\right)^{2} \geq\left(\frac{a-2 w_{j k}+w_{j l}}{3}\right)^{2}
$$

Upstream firm $i$ could increase its payoff by setting $w_{i k}^{\prime}=\frac{a}{2}$ and $w_{i l}^{\prime}=a$. In this case, the matches will remain because

$$
\frac{a^{2}}{16}>\left(\frac{a-w_{i k}}{2}\right)^{2} \geq\left(\frac{a-2 w_{j k}+w_{j l}}{3}\right)^{2}
$$

Hence, the deviation would be profitable, as $w_{i k}^{\prime}\left(\frac{a-w_{i k}^{\prime}}{2}\right)>w_{i k}\left(\frac{a-w_{i k}}{2}\right)$.

Third, we show that the equilibrium wholesale prices paid by retailers can not be such that one retailer pays $\frac{a}{2}$ and the other pays less than $\frac{a}{2}$. Consider an equilibrium vector of wholesale prices with matches $(k, i)$ and $(l, j)$ and $w_{i k}<w_{j l}=\frac{a}{2}$. This implies that:

$$
\left(\frac{a-w_{i k}}{2}\right)^{2} \geq\left(\frac{\frac{3 a}{2}-2 w_{j k}}{3}\right)^{2}
$$

To prove that upstream $i$ has a profitable deviation we distinguish two cases:

Case 1: $\left(\frac{a-w_{i k}}{2}\right)^{2}>\left(\frac{\frac{3 a}{2}-2 w_{j k}}{3}\right)^{2}$. Upstream firm $i$ can increase its payoff by setting $w_{i l}^{\prime}=a$ and $w_{i k}^{\prime}=w_{i k}+\varepsilon$, where $0<\varepsilon<\min \left\{\frac{a}{2}-w_{i k}, \frac{4 w_{j k}-3 w_{i k}}{3}\right\}$. In this subgame, retailer $l$ chooses upstream $j$ and retailer $i$ upstream $k$, because:

$$
\left(\frac{a-w_{i k}^{\prime}}{2}\right)^{2}>\left(\frac{a-w_{i k}-\left(\frac{4 w_{j k}-3 w_{i k}}{3}\right)}{2}\right)^{2}=\left(\frac{\frac{3 a}{2}-2 w_{j k}}{3}\right)^{2}
$$


As $w_{i k}^{\prime}\left(\frac{a-w_{i k}^{\prime}}{2}\right)>w_{i k}\left(\frac{a-w_{i k}}{2}\right)$, the deviation is profitable.

Case 2: $\left(\frac{a-w_{i k}}{2}\right)^{2}=\left(\frac{\frac{3 a}{2}-2 w_{j k}}{3}\right)^{2}$. This implies that $w_{j k}<w_{i k}$. Upstream firm $i$ can increase its payoff by setting $w_{i k}^{\prime}=a$ and $w_{i l}^{\prime}=w_{i k}+\varepsilon$, where $0<\varepsilon<\min \left\{\frac{a}{2}-w_{i k}, \frac{3 a-3 w_{i k}-2 w_{j k}}{3}\right\}$. In this subgame, retailer $k$ chooses upstream firm $j$ and retailer $l$ would match with firm $i$, because:

$$
\left(\frac{a-w_{i l}^{\prime}}{2}\right)^{2}>\left(\frac{a-w_{i k}-\left(\frac{3 a-3 w_{i k}-2 w_{j k}}{3}\right)}{2}\right)^{2}=\left(\frac{w_{j k}}{3}\right)^{2}
$$

As $w_{i l}^{\prime}\left(\frac{a-w_{i l}^{\prime}}{2}\right)>w_{i k}\left(\frac{a-w_{i k}}{2}\right)$, the deviation is profitable. Observe that $3 a-3 w_{i k}-2 w_{j k}>0$, because $w_{j k}<w_{i k}<\frac{a}{2}$.

Lemma $4 w_{11}=w_{12}=w_{21}=w_{22}=\frac{a}{2}$ is an equilibrium in the subgame $(1,1)$.

Given these wholesale prices, retailers will choose different suppliers in Stage 3 (they obtain the monopoly profits whereas they would obtain the duopoly profits when selecting the same upstream firm). Given that it serves only one retailer, supplier $i$ maximizes profits by setting a wholesale price equal to $\frac{a}{2}$, because $\arg \max _{w} \frac{(a-w) w}{2}=\frac{a}{2}$. This yields profits of $\frac{a^{2}}{8}$. Therefore, the only deviation we have to check is whether this supplier can increase profits when attracting both retailers by reducing the wholesale prices. In this case, its maximization program is given by:

$$
\begin{aligned}
\operatorname{Max}_{w_{i 1}, w_{i 2}} f\left(w_{i 1}, w_{i 2}\right) & =w_{i 1}\left(\frac{a-2 w_{i 1}+w_{i 2}}{3}\right)+w_{i 2}\left(\frac{a-2 w_{i 2}+w_{i 1}}{3}\right) \\
\text { s.t. }\left(\frac{a-2 w_{i 1}+w_{i 2}}{3}\right)^{2} & \geq\left(\frac{a}{4}\right)^{2} \\
\left(\frac{a-2 w_{i 2}+w_{i 1}}{3}\right)^{2} & \geq\left(\frac{a}{4}\right)^{2} \\
w_{i 1}, w_{i 2} & \geq 0
\end{aligned}
$$

The first two restrictions refer to the fact that both retailers should obtain at least the same profits by choosing supplier $i$ than by selecting supplier $j$ and acting as a monopolist. The supplier's maximization problem can be simplified and rewritten as: 


$$
\begin{aligned}
{\underset{w}{w_{i 1}, w_{i 2}}}_{\operatorname{Max}} f\left(w_{i 1}, w_{i 2}\right) & =w_{i 1}\left(\frac{a-2 w_{i 1}+w_{i 2}}{3}\right)+w_{i 2}\left(\frac{a-2 w_{i 2}+w_{i 1}}{3}\right) \\
\text { s.t. }-\frac{a}{4} & \geq-\left(\frac{a-2 w_{i 1}+w_{i 2}}{3}\right) \\
-\frac{a}{4} & \geq-\left(\frac{a-2 w_{i 2}+w i_{1}}{3}\right) \\
w_{i 1}, w_{i 2} & \geq 0
\end{aligned}
$$

We can write the Lagrangian function Z:

$$
Z=f\left(w_{i 1}, w_{i 2}\right)+\lambda_{1}\left(-\frac{a}{4}+\left(\frac{a-2 w_{i 1}+w_{i 2}}{3}\right)\right)+\lambda_{2}\left(-\frac{a}{4}+\left(\frac{a-2 w_{i 2}+w_{i 1}}{3}\right)\right)
$$

Then, the Kuhn-Tucker conditions are given by $(k=1,2)$ :

$$
\begin{array}{ll}
\frac{\partial Z}{\partial w_{i k}} \leq 0 & w_{i k} \geq 0 \text { and } w_{i k} \frac{\partial Z}{\partial w_{i k}}=0 \\
\frac{\partial Z}{\partial \lambda_{k}} \geq 0 & \lambda_{k} \geq 0 \text { and } \lambda_{k} \frac{\partial Z}{\partial \lambda_{k}}=0
\end{array}
$$

So we have to find values for the wholesale prices and the Lagrange multipliers that satisfy these conditions. Asssume that the solution is such that wholesale prices are positive, then $\frac{\partial Z}{\partial w_{i k}}=0$. We solve the system of equations formed by

$$
\frac{\partial Z}{\partial w_{i 1}}=0, \frac{\partial Z}{\partial w_{i 2}}=0, \lambda_{1} \frac{\partial Z}{\partial \lambda_{1}}=0 \text { and } \lambda_{2} \frac{\partial Z}{\partial \lambda_{2}}=0
$$

We obtain four solutions:

$$
\begin{aligned}
& w_{i 1}=\frac{a}{4}, w_{i 2}=\frac{a}{4}, \lambda_{1}=\frac{a}{2} \text { and } \lambda_{2}=\frac{a}{2} \\
& w_{i 1}=\frac{a}{2}, w_{i 2}=\frac{3 a}{8}, \lambda_{1}=\frac{a}{4} \text { and } \lambda_{2}=0 \\
& w_{i 1}=\frac{3 a}{8}, w_{i 2}=\frac{a}{2}, \lambda_{1}=0 \text { and } \lambda_{2}=\frac{a}{4} \\
& w_{i 1}=\frac{a}{2}, w_{i 2}=\frac{a}{2}, \lambda_{1}=0 \text { and } \lambda_{2}=0
\end{aligned}
$$


Only the first one satisfies $\frac{\partial Z}{\partial \lambda_{1}} \geq 0$ and $\frac{\partial Z}{\partial \lambda_{2}} \geq 0$. So, the optimal wholesale prices if the supplier wants to deviate and serve both retailers are $w_{i 1}^{*}=w_{i 2}^{*}=\frac{a}{4}$. Therefore, it obtains a profit of $\frac{a^{2}}{8}$, which is not higher (in fact, it is equal) to the profits obtained by serving to only one retailer. Therefore, such a deviation is not profitable.

\subsection{Appendix 2 (competition in prices)}

The case $(1,2)$

Proposition $7 w_{11}=w_{21}=\frac{a}{4}$ and $w_{12}=w_{22}=\frac{a}{2}$ are the equilibrium wholesale prices in the subgame (1,2).

Upstream firm $i$ may always obtain $\frac{a^{2}}{8}$ by choosing $w_{i 1}=a$ and $w_{i 2}=\frac{a}{2}$. Then, if in equilibrium upstream firm i is not chosen by $1, w_{i 2}=\frac{a}{2}$. Then, we obtain the optimal wholesale prices of upstream firm $\mathrm{j}$ if it sells to 1 , given $w_{i 1}$ and $w_{i 2}=\frac{a}{2}$. We assume that, in case of indifference, retailer 1 chooses upstream $j$. If $w_{i 1} \geq \frac{a}{2}$, then $w_{j 1}=w_{j 2}=\frac{a}{2}$ and producer $\mathrm{j}$ obtains the monopoly profits. If $w_{i 1}<\frac{a}{2}$, in order to attract retailer 1 , producer $j$ should set $w_{j 2}>w_{j 1}$. Upstream firm $\mathrm{j}$ solves the following maximization program, where it maximizes its profits (given that good $\mathrm{j}$ will be sold at price $w_{j 2}$ ) subject to the constraint that retailer 1 prefers to choose upstream firm $\mathrm{j}$ rather than upstream firm i:

$$
\begin{aligned}
& {\underset{w}{w_{11}, w_{j 2}}}_{\operatorname{Max}} f\left(w_{j 1}, w_{j 2}\right)=\left(a-w_{j 2}\right) w_{j 1} \\
\text { s.t. }\left(w_{j 2}-w_{j 1}\right)\left(a-w_{j 2}\right) \geq & \left(\frac{a}{2}-w_{i 1}\right)\left(\frac{a}{2}\right) \\
w_{j 1}, w_{j 2} \geq & 0
\end{aligned}
$$

The maximization problem of the supplier can be rewritten as: 


$$
\begin{aligned}
& \operatorname{Max}_{w_{j 1}, w_{j 2}} f\left(w_{j 1}, w_{j 2}\right)=\left(a-w_{j 2}\right) w_{j 1} \\
\text { s.t. }-\left(\frac{a}{2}-w_{i 1}\right)\left(\frac{a}{2}\right) \geq & -\left(w_{j 2}-w_{j 1}\right)\left(a-w_{j 2}\right) \\
w_{j 1}, w_{j 2} \geq & 0
\end{aligned}
$$

We can write the Lagrangian function Z:

$$
Z=f\left(w_{i 1}, w i_{2}\right)+\lambda\left(-\left(\frac{a}{2}-w_{i 1}\right)\left(\frac{a}{2}\right)+\left(w_{j 2}-w_{j 1}\right)\left(a-w_{j 2}\right)\right)
$$

Then, the Kuhn-Tucker conditions are given by $(k=1,2)$ :

$$
\begin{aligned}
\frac{\partial Z}{\partial w_{j k}} \leq 0 & w_{j k} \geq 0 \text { and } w_{j k} \frac{\partial Z}{\partial w_{j k}}=0 \\
\frac{\partial Z}{\partial \lambda} \geq 0 & \lambda \geq 0 \text { and } \lambda \frac{\partial Z}{\partial \lambda}=0
\end{aligned}
$$

So we have to find values for the wholesale prices and the Lagrange multiplier that satisfy these conditions. Assume that the solution is such that the wholesale prices are positive, then $\frac{\partial Z}{\partial w_{j k}}=0$. We solve the system of equations formed by:

$$
\frac{\partial Z}{\partial w_{j 1}}=0, \frac{\partial Z}{\partial w_{j 2}}=0 \text { and } \lambda \frac{\partial Z}{\partial \lambda}=0
$$

We obtain two solutions:

$$
\begin{aligned}
& w_{j 1}=0, w_{j 2}=a \text { and } \lambda=0 \\
& w_{j 1}=w_{i 1}, w_{j 2}=\frac{a}{2} \text { and } \lambda=1
\end{aligned}
$$

We can diregard the first solution, because $\frac{\partial Z}{\partial \lambda}<0$. The second solution satifies all conditions given that $\frac{\partial Z}{\partial \lambda} \geq 0$. Summarizing, the optimal wholesale prices for firm $j$ are $w_{j 1}=w_{i 1}, w_{j 2}=\frac{a}{2}$ if $w_{i 1}<\frac{a}{2}$. So, in equilibrium, both upstream firms will charge $\frac{a}{2}$ to retailer $2\left(w_{12}=w_{22}=\frac{a}{2}\right)$ 
and the same wholesale price $w$ to retailer $1\left(w_{11}=w_{21}=w\right)$. To obtain the equilibrium value of $w$, we have to impose the condition that the producer supplying to two retailers obtains the same profit as the producer supplying to only one retailer i.e.: $\left(a-\frac{a}{2}\right) w=\frac{a^{2}}{8}$. The solution to this equation is $w=\frac{a}{4}$. Then, in equilibrium, we have that $w_{11}=w_{21}=\frac{a}{4}$ and $w_{12}=w_{22}=\frac{a}{2}$.

The case $(1,1)$

Proposition 8 In the subgame (1,1) each supplier sells to a different retailer at a wholesale price equal to $\frac{a}{2}$.

Given a vector of wholesale prices, the retailers will choose different producers. If both choose the same producer, at least one retailer would make zero profits and it could obtain positive profits just by choosing the other producer. Given this, the optimal wholesale prices for producer $i$ is $w_{i 1}=w_{i 2}=\frac{a}{2}$ and it obtains a profit of $\frac{a^{2}}{8}$.

\subsection{Appendix 3 (calculations)}

\subsubsection{Section 3}

We next calculate the profits of both retailers and upstream firms, and social welfare for the different possible assortment choices (we must take into account that the situation with a merger is like scenario $(1,0)$ when the merged entity commits to sell only one good and like the scenario $(2,0)$, when it does not restrict assortment):

Subgame $(1,0)$ : the wholesale prices are $w_{11}=w_{21}=0$. Retailer 1 sells $\frac{a}{2}$ of one of the goods and obtains profits of $\left(\frac{a}{2}\right)^{2}$. Upstream firms obtain zero profits. Social welfare is given by the area below the demand: $\left(\frac{a}{2}\right)^{2}+\left(\frac{a}{2}\right)^{2}\left(\frac{1}{2}\right)=\left(\frac{3}{2}\right)\left(\frac{a}{2}\right)^{2}=\frac{3 a^{2}}{8}=0.375 a^{2}$

Subgame $(2,0)$ : the wholesale prices are $w_{11}=w_{21}=\frac{a}{2}$. Retailer 1 sells $x_{11}=x_{21}=$ $\frac{a-\frac{a}{2}}{2}=\frac{a}{4}$. The profits of retailer 1 are $2\left(\frac{a}{4}\right)^{2}=\frac{a^{2}}{8}$ and the the profits of each upstream firm are 
$\left(\frac{a}{2}\right)\left(\frac{a}{4}\right)=\frac{a^{2}}{8}$. Social welfare is given by $2\left(\left(\frac{a}{4}\right)^{2}\left(\frac{1}{2}\right)+\frac{3 a^{2}}{16}\right)=\frac{a^{2}}{16}+\frac{3 a^{2}}{8}=\frac{7 a^{2}}{16}=0,4375 a^{2}$.

Subgame $(1,1)$ : retailers sell different goods and pay for the good they sell a wholesale price $\frac{a}{2}$. Each retailer sells $\frac{a}{4}$ of different goods. Profits of each retailer are $\left(\frac{a}{4}\right)^{2}$. Profits of upstream firms and social welfare are like in $(2,0)$.

Subgame $(1,2)$ : the wholesale prices are $w_{11}=w_{21}=\frac{a}{4}$ and $w_{12}=w_{22}=\frac{a}{2}$. Retailer 1 sells the quantity $x_{i 1}=\frac{a-2\left(\frac{a}{4}\right)+\frac{a}{2}}{3}=\frac{a}{3}$ of only one good; retailer 2 sells $x_{i 2}=\frac{a-2\left(\frac{a}{2}\right)+\frac{a}{4}}{3}=$ $\frac{a}{12}$ of the same good and total output of this good is $\frac{5 a}{12}$. Only retailer 2 sells the amount $x_{j 2}=\frac{a-\frac{a}{2}}{2}=\frac{a}{4}$ of the other good. Profits of retailer 1 are given by $\left(\frac{a}{3}\right)^{2}$ and profits of retailer 2 by $\left(\frac{a}{12}\right)^{2}+\left(\frac{a}{4}\right)^{2}=\frac{5 a^{2}}{72}$. Profits of the upstream firm supplying to both retailers are $\left(\frac{a}{4}\right)\left(\frac{a}{3}\right)+\left(\frac{a}{2}\right)\left(\frac{a}{12}\right)=\left(\frac{a^{2}}{12}\right)+\left(\frac{a^{2}}{24}\right)=\frac{a^{2}}{8}$. Profits of the upstream firm supplying to only one retailer are $\left(\frac{a}{2}\right)\left(\frac{a}{4}\right)=\frac{a^{2}}{8}$. Social welfare is the area below the demands of the two goods: $\left(\frac{5 a}{12}\right)^{2}\left(\frac{1}{2}\right)+\frac{35 a^{2}}{144}+\left(\frac{a}{4}\right)^{2}\left(\frac{1}{2}\right)+\frac{3 a^{2}}{16}=\frac{95 a^{2}}{288}+\frac{7 a^{2}}{32}=\frac{79 a^{2}}{144}=0.54861 a^{2}$.

Subgame $(2,2)$ : the wholesale prices are $w_{11}=w_{21}=w_{12}=w_{22}=\frac{a}{2}$. Each retailer sells $x_{i j}=\left(\frac{a-\frac{a}{2}}{3}\right)=\frac{a}{6}$ of each good. The profits of each retailer are $\frac{a^{2}}{18}$ and the profits of each upstream firm are $\left(\frac{a}{2}\right)\left(\frac{a}{3}\right)=\frac{a^{2}}{6}$. Finally, social welfare is given by $2\left(\left(\frac{a^{2}}{9}\right)\left(\frac{1}{2}\right)+\frac{2 a^{2}}{9}\right)=$ $\frac{a^{2}}{9}+\frac{4 a^{2}}{9}=\frac{5 a^{2}}{9}=0.5555 a^{2}$.

\subsubsection{Section 4}

We calculate the profits of both retailers and upstream firms and social welfare for the different possible assortment choices, given that upstream firms have merged:

Subgames $(2,2),(2,0)$ and $(1,1)$ : the situation is like the one we had in Section 3.

Subgame $(1,0)$ : retailer 1 pays a wholesale price $\frac{a}{2}$ and sells $\frac{a}{4}$. Its profits are $\left(\frac{a}{4}\right)^{2}$ and the profits of the upstream firm are $\left(\frac{a}{2}\right)\left(\frac{a}{4}\right)=\frac{a^{2}}{8}$. Social welfare is half the one we had in $(2,0)$ $\frac{7 a^{2}}{32}=0.21875 a^{2}$. 
Subgame $(1,2)$ : retailers pay for all the goods a wholesale price $\frac{a}{2}$. Retailer 1 sells $\frac{a-\frac{a}{2}}{3}=\frac{a}{6}$ and retailer 2 sells $\frac{a}{6}$ of the good sold by retailer 1 and $\frac{a-\frac{a}{2}}{2}=\frac{a}{4}$ of the other good. Retailer 1 obtains profits $\frac{a^{2}}{36}$ and retailer 2 profits $\frac{a^{2}}{36}+\frac{a^{2}}{16}$. The upstream firm obtains profits $\frac{a}{2}\left(\frac{a}{3}+\frac{a}{4}\right)=$ $\frac{7 a^{2}}{24}$. Finally, social welfare is given by: $\left(\frac{a}{4}\right)^{2}\left(\frac{1}{2}\right)+\frac{3 a^{2}}{16}+\left(\frac{a^{2}}{9}\right)\left(\frac{1}{2}\right)+\frac{2 a^{2}}{9}=\frac{143 a^{2}}{288}=0.496528 a^{2}$.

\subsubsection{Section 5.2}

We calculate the profits of both retailers and upstream firms and social welfare for the different possible assortment choices:

Subgames $(1,0),(2,0)$ and $(1,1)$ : the situation is like the one we had in Section 3.

Subgame $(1,2)$ : the wholesale prices are $w_{11}=w_{21}=\frac{a}{4}$ and $w_{12}=w_{22}=\frac{a}{2}$. Price in one market is $\frac{a}{2}$ and $\frac{3 a}{4}$ in the other one. Profits of retailer 1 are $\left(\frac{a}{2}-\frac{a}{4}\right)\left(\frac{a}{2}\right)=\frac{a^{2}}{8}$ and retailer 2 gets the same profit it obtains in the scenario $(1,1):\left(\frac{a}{4}\right)^{2}$. Profits of the upstream firm whose good is sold at price $\frac{a}{2}$ are $\left(\frac{a}{2}\right)\left(\frac{a}{4}\right)=\frac{a^{2}}{8}$. Profits of the upstream firms whose good is sold at price $\frac{3 a}{4}$ are $\left(\frac{a}{4}\right)\left(\frac{a}{2}\right)=\frac{a^{2}}{8}$. Social welfare in the low price market is like the one in the scenario $(1,0)$ and, in the other market, social welfare is half the one we had in the scenario $(2,0)$. Therefore, it amounts to $\frac{3 a^{2}}{8}+\frac{7 a^{2}}{32}=\frac{19 a^{2}}{32}=0.59375 a^{2}$.

Subgame $(2,2)$ : the wholesale prices are $w_{11}=w_{21}=w_{12}=w_{22}=\frac{a}{2}$. In each market, the price is $\frac{a}{2}$ (the monopoly price). Each upstream firm obtains the monopoly profits $\left(\frac{a}{2}\right)^{2}$ and retailers zero profits. Social welfare doubles the one we had in the scenario $(1,0)$, when only one market was monopolized $\frac{3 a^{2}}{4}=0.75 a^{2}$.

\section{References}

Argentesi, E., Buccirossi, P., Cervone, R., Duso, T., Marrazzo, A. (2016). "The effect of retail mergers on prices and variety: An ex-post evaluation", DICE Discussion Paper, No. 225, ISBN 
978-3-86304-224-0.

Avenel E. and Caprice, S. (2006), "Upstream market power and product line differentiation in retailing", International Journal of Industrial Organization 24 (2), 319-334.

Avignon R., Allain M. L. and Chambolle C. (2019). "Buying groups and product variety", W.P. available at http://chambolle.io/wp-content/uploads/2019/10/Buying_groups.

Cleeren, K., Verboven, F., Dekimpe, M.G. and Gielens, K. (2010). "Intra- and Interformat Competition Among Discounters and Supermarkets". Marketing Science 29 (3), 456-473.

Cong Pan (2019). "Manufacturer's direct distribution with incumbent retailer's product line choice", Economics Letters 174, 136-139.

Dana, J.D. (2012). "Buyer groups as strategic commitments", Games and Economic Behavior $74,470-485$.

Dukes, A., Geylani, T. and Srinivasan, K. (2009). "Strategic Assortment Reduction by a Dominant Retailer", Marketing Science 28 (2), 309-319.

European Commission (2005). "Coca-Cola: Europe-wide remedies in Özzy drinks", decision addressed to the Coca-Cola Company, https://ec.europa.eu/competition/publications/cpn/20

Fernie, J., Fernie, S. and Moore, C. (2003). "Principles of Retailing", edited by ButterworthHeinemann.

Fishman, C. (2006). "The Wal-Mart Effect and a Decent Society: Who Knew Shopping Was So Important?", Academy of Management Perspectives 20 (3), 6-25.

Gabrielsen, T.S. and Sorgard, L. (1999). "Discount chains and brand policy", Scandinavian Journal of Economics 101 (1), 127-142.

Horn, H. , and Wolinsky, A. (1988). "Bilateral Monopolies and Incentives for Merger", RAND Journal of Economics 19 (3), 408-19.

Igami, M. (2011). "Does big drives out small? Entry, exit and differentiation in the super- 
market industry", Review of Industrial Organization 38, 1-21.

Inderst, R. and Shaffer G. (2007). "Retail mergers, buyer power and product variety", The Economic Journal 117, 45-67.

Iozzi, A. and Valetti, T. (2014). "Vertical bargaining and countervailing power", American Economic Journal: Microeconomics 6 (3), 106-135.

Johansen, B.O. and Nilssen, T. (2016) "The economics of retailing formats: competition vs. bargaining" The Journal of Industrial Economics 64 (1), 109-134.

Johnson, W. C. (1988). "Sales promotions: It comes down to push marketing", Marketing News, February 8.

Kadiyali, V., Chintagunta, P. and Vilcassim, N. (2000). "Manufacturer-Retailer chanel interactions and implications for chanel power: an empirical investigation of pricing in a local market", Marketing Science 19 (2), 127-148.

Marx, L.M. and Shaffer, G. (2010). "Slotting allowances and scarce shelf space", Journal of Economics \& Management Strategy 19 (3), 575-603.

Mathewson, F. and Winter, R. (1987). "The Competitive Effects of Vertical Agreements: Comment", American Economic Review 77, 1057-1062.

Mauleon, A., Sempere-Monerris. J.J. and Vannetelbosch, V.J. (2011). "Networks of manufacturers and retailers", Journal of Economic Behavior \& Organization 77, 351-367.

Messinger, P. and Narasimhan, C. (1995)."Has Power Shifted in the Grocery Channel?" Marketing Science 14 (2), 189-223.

Miklós-Thal, J., Rey, P., and Vergé, T. (2011) "Buyer Power and Intrabrand Competition." Journal of the European Economic Association 9, 721-741.

Milliou, C. and Sandonis, J. (2018). "Manufacturer Mergers and Product Variety in Vertically Related Markets", Journal of Industry, Competition and Trade 18 (1),1-24. 
Moner-Colonques, R., Sempere-Monerris, J.J. and Urbano, A. (2004). "The manufacturers' Choice of Distribution Policy under successive duopoly", Southern Economic Journal 70 (3), $532-548$.

Moner-Colonques, R., Sempere-Monerris, J.J. and Urbano, A. (2011). "Product Line Choice in Retail Duopoly", Journal of Economics \& Management Strategy 20 (3), 777-802.

Rhodes, A and Zhou, J. (2019). "Consumer Search and Retail Market Structure". Management Science 65 (6), 2445-2945.

Rey P. and Vergé, T. (2019), "Secret contracting in multilateral relations", TSEWorking Paper, n 16-744, revised Nov. 2019, available at https://www.tse-fr.eu/sites/default/... les/TSE/documents/doc/

Rey, P and Whinston, M. D. (2013). "Does retailer power lead to exclusion". Rand Jornal of Economics 44 (1), 75-81.

Varian, H. (1980). "A model of sales", The American Economic Review 70 (4), 651-659. 